\title{
openheart Prerace aspirin to protect susceptible runners from cardiac arrest during marathons: is opportunity knocking?
}

\author{
Arthur J Siegel $1^{1,2}$
}

To cite: Siegel AJ. Prerace aspirin to protect susceptible runners from cardiac arrest during marathons: is opportunity knocking?. Open Heart 2015;2:e000102. doi:10.1136/openhrt-2014000102

Received 27 March 2014 Revised 6 February 2015 Accepted 5 June 2015
CrossMark

\begin{abstract}
${ }^{1}$ Internal Medicine, McLean Hospital, Belmont, Massachusetts, USA ${ }^{2}$ Harvard Medical School, Boston, Massachusetts, USA
\end{abstract}

Correspondence to Dr Arthur J Siegel; asiegel@partners.org

\section{ABSTRACT}

While endurance exercise such as marathon training is cardioprotective, an increasing frequency of racerelated cardiac arrests and sudden death has been observed in middle-aged men since the year 2000. An evidence-based strategy for prevention is considered based on identifying atherothrombosis as the underlying cause in this susceptible subgroup. Review of all articles on PubMed related to acute cardiac events during marathons. Male gender and the marathon compared with the half-marathon were identified as significant risk factors for race-related cardiac arrests, which events increased 2.3-fold in the latter half of a 10-year prospective registry beginning in the year 2000 . There were 50 cardiac arrests in runners who were $86 \%$ male with a mean age of 42 years. The main cause of sudden death was atherosclerotic heart disease in those over the age of 40 including myocardial infarction in 12 of $13(93 \%)$ cases over the age of 45 as assessed retrospectively. Inflammatory biomarkers predicting acute cardiac events and hypercoagulability with in vivo platelet activation were demonstrated in same-aged asymptomatic middle-aged men during marathons. Excess cardiac morbidity and mortality in middle-aged men during marathons is mediated by atherothrombosis which may render nonobstructive coronary atherosclerotic plaques vulnerable to rupture. Prerace low-dose aspirin usage is prudent to protect susceptible runners from a high, if transient, risk for cardiac arrest during races as evidence-based to prevent first myocardial infarctions in same-aged healthy men.

\section{CARDIAC ARRESTS HAVE INCREASED IN} FREQUENCY IN MIDDLE-AGED MEN DURING MARATHONS SINCE THE YEAR 2000 WITH ATHEROSCLEROTIC CORONARY ARTERY DISEASE AS THE MAIN CAUSE OF SUDDEN DEATH

While leisure-time running reduces all-cause and cardiovascular mortality risk, ${ }^{1}$ an increased frequency of cardiac arrest and sudden death has been observed in middle-aged men during marathons since the year $2000 .^{2}{ }^{3}$ A 10 -year prospective registry of long-distance running races showed that male gender and the marathon as opposed to the half-marathon were significant risk factors for cardiac arrest. ${ }^{2}$ Such events increased 2.3-fold in middle-aged men in the latter half of the study in runners with an average age of 42 years. Cardiac arrest also increased from 1 in 29000 to 1 in 22000 in men over the age of 29 , comparing decades before and after the year 2000 at two specific marathon venues. ${ }^{3}$

Atherosclerotic heart disease was the main cause of marathon-related sudden cardiac death in participants over the age of 40 in two retrospective studies in contrast to mostly nonpreventable causes in younger athletes. ${ }^{4-7}$ These studies clearly demonstrate an increasing frequency of race-related cardiac arrests in middle-aged men in contrast to a declining rate of sudden cardiac deaths in the general population. ${ }^{8}$

\section{BIOMARKERS PREDICTING ACUTE CARDIAC EVENTS IN HEALTHY PERSONS ARE TRANSIENTLY ELEVATED IN ASYMPTOMATIC MIDDLE-AGED MEN DURING MARATHONS}

Middle-aged male physician-runners who were attendees at prerace symposia of the American Medical Athletic Association provided prerace and postrace blood samples for analysis at sequential Boston marathons. ${ }^{9}$ Postrace elevations in creatine kinase as an index of exertional rhabdomyolysis in these asymptomatic respondents were accompanied by neutrophilia with elevated interleukin 6 and $\mathrm{C}$ reactive protein as inflammatory biomarkers predicting cardiovascular events in healthy persons. ${ }^{10-14}$ Elevated fibrinogen, von Willebrand factor and D-dimer with in vivo platelet activation indicated a haemostatic imbalance with procoagulant effects. ${ }^{15} 16$ A biomarker profile representing a 'perfect storm' for an acute coronary syndrome was present in these asymptomatic runners who also showed concurrent release of cardiac troponin $\mathrm{T}$ and $\mathrm{N}$-terminal probrain natriuretic peptide. ${ }^{17}$ 
Perhaps reprising the index case of Pheidippides in 490 B.C., (figure 1) these findings indicate a high, if transient, risk for atherothrombosis during marathons, which may cause low-profile coronary atherosclerotic plaques to morph into the culprit lesions of acute coronary thrombosis. ${ }^{18}{ }^{19}$ Coronary plaque rupture triggering type 1 acute myocardial infarction was observed in vivo in two runners during postrace coronary angiography after the 2011 Boston marathon. ${ }^{20} 21$ The increase in cardiac arrests in susceptible runners during marathons may be seen as a specific clinical example of exertional sudden cardiac death as occurs in on-duty police officers. $^{22}{ }^{23}$ Inflammation-induced atherothrombosis also accounts for the increased cardiac risk of systemic infections such as community-acquired bacteraemia and scrub typhus. ${ }^{24} 25$

\section{ASPIRIN USAGE IS CARDIOPROTECTIVE DURING SHORT-TERM HIGH RISK DUE TO SYSTEMIC INFLAMIMATION}

Aspirin usage has been shown to decrease 30-day cardiac mortality in critically ill patients with sepsis and to reduce the morbidity and mortality of pre-eclampsia by $30 \%$ in an evidence-based review for the US Preventive Service Task Force. ${ }^{26}{ }^{27}$ These systematic reviews provide a rationale for recommending prerace aspirin usage to offset high short-term cardiac risk in susceptible middle-aged men during marathons as has recently been proposed for serious systemic infections. ${ }^{28-31}$ This strategy qualifies as concordant with primary aspirin prophylaxis endorsed for high-risk subgroups based on appropriate risk stratification by the American Heart Association (AHA) and the Working Group on Thrombosis of the European Society of Cardiology. ${ }^{32} 33$ These recommendations rightfully apply to the high risk for major cardiovascular events due to inflammation-induced atherothrombosis in both shortterm and chronic clinical conditions as recently demonstrated in patients with rheumatological disorders in a population-based cohort study. ${ }^{34}$

\section{SHOULD SUSCEPTIBLE RUNNERS TAKE PRERACE ASPIRIN TO PREVENT CARDIAC ARREST DURING MARATHONS?}

The rationale for recommending prerace aspirin usage to protect susceptible middle-aged men from short-term high risk for exertional myocardial infarctions rests on conclusive evidence for prevention of first acute myocardial infarctions in same-aged healthy men in the prospective randomised controlled Physicians Health Study (PHS) ${ }^{35}$ This strategy also confers a class 1 recommendation for prehospital treatment in case an acute coronary syndrome arises especially near the finish line where most cardiac arrests take place. ${ }^{36} 37$ A single low-dose

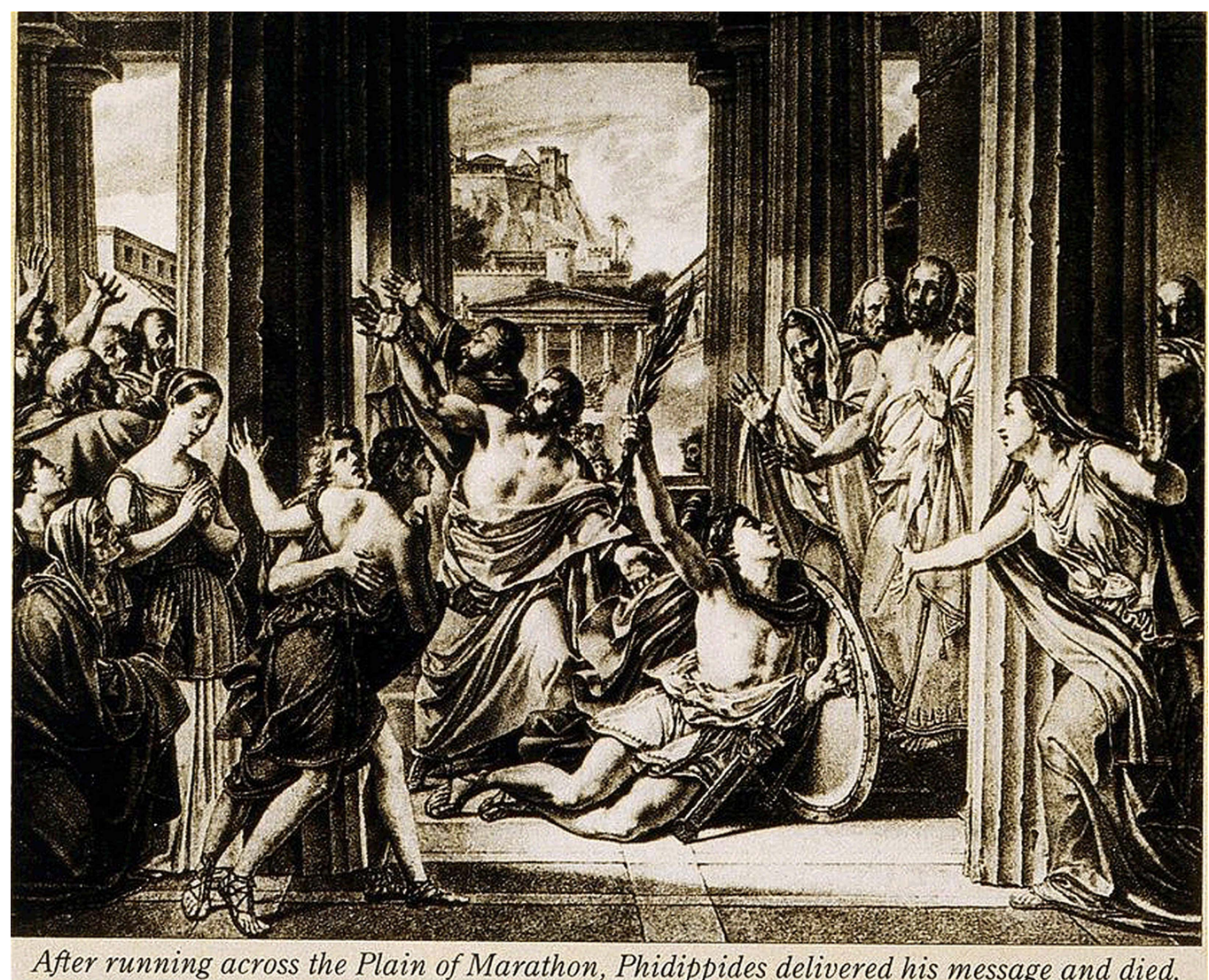

Figure 1 Pheidippides' sudden cardiac death in the Atheneum in 490 B.C. after declaring victory over the invading Persian army on the Plains of Marathon (by anonymous). 
- If cardiac arrests during marathons are due to atherosclerotic heart disease in some middle-aged men

- And same-aged asymptomatic marathoners show biomarkers of inflammation during races which predict cardiovascular events in healthy persons

- And aspirin has been conclusively shown to prevent first myocardial infarctions in healthy men

- Pre-race aspirin usage may protect susceptible runners from cardiac arrest.

Figure 2 Rationale for prerace aspirin usage to protect susceptible runners from cardiac arrest during marathons

aspirin would provide antithrombotic benefit during and for the $24 \mathrm{~h}$ of highest postrace cardiac risk even if taken at the starting line so long as it is not enteric coated. ${ }^{38}$ Low-dose aspirin confers antithrombotic benefit by irreversibly inhibiting platelet cyclo-oxygenase with minimal exposure to adverse effects such as gastrointestinal bleeding or renal injury during dehydration. ${ }^{39}$

Analogous to the urgent advisory by the US Food and Drug Administration on excess sudden cardiac death associated with short-course azithromycin, ${ }^{40}{ }^{41}$ what message should be conveyed to susceptible males regarding this same risk during marathon running? The recommendation for middle-aged men to take prerace aspirin on approval by their physicians was provided in the programme of the 2014 Rio de Janeiro marathon by its medical director, Paulo Afonso Lourega de Menezes. ${ }^{42}$ As with excess sudden cardiac death with azithromycin, disclosure allows susceptible males to participate cognisant of transiently high short-term cardiac risk and with the benefit of cardioprotective measures (figure 2). ${ }^{43}$

Endorsed by a group of international marathon medical directors based on clinical urgency, ${ }^{44}{ }^{45}$ this measure presents an opportunity to decrease cardiac morbidity and mortality in susceptible males at high risk by appropriate risk stratification as has been achieved through a consensus process in the marathon medical community for exercise-associated hyponatremia. ${ }^{46} 47$

\section{Overview}

The rationale for prerace aspirin usage in middle-aged men before marathons links recent evidence demonstrating an increased risk for cardiac arrest and sudden death in this subgroup to elevated biomarkers predicting cardiac events in same-aged asymptomatic males during races. Prerace aspirin usage for high short-term cardiac risk is concordant with evidence for reduced short-term cardiac risk during inflammation and is concordant with subspecialty guidelines endorsing aspirin for primary prevention in subgroups at high risk by appropriate risk stratification. Pending results of a prospective randomised trial specifically in runners, a prudent strategy for susceptible runners would be to take a prerace low-dose aspirin on approval by their physicians.

Competing interests None declared.

Provenance and peer review Not commissioned; externally peer reviewed.

Open Access This is an Open Access article distributed in accordance with the Creative Commons Attribution Non Commercial (CC BY-NC 4.0) license, which permits others to distribute, remix, adapt, build upon this work noncommercially, and license their derivative works on different terms, provided the original work is properly cited and the use is non-commercial. See: http:// creativecommons.org/licenses/by-nc/4.0/

\section{REFERENCES}

1. Lee D, Pate RR, Levie CJ, et al. Leisure-time running reduces all-cause and cardiovascular mortality risk. J Am Coll Cardiol 2014;64:472-81.

2. Kim JH, Malhotra R, Chiampas G, et al. for the RACER Study Group. Cardiac arrest during long-distance running races. New Engl J Med 2012;36:130-42.

3. Roberts WO, Roberts DM, Lunos S. Marathon related cardiac arrest differences in men and women. Br J Sports Med 2013;47:168-71.

4. Mathews SC, Narotsky DL, Berbholt DL, et al. Mortality among marathon runners in the United States, 2000-2009. Am J Sports Med 2012;40:1495-500.

5. Webner D, Duprey KM, Drezner JA, et al. Sudden cardiac arrest and death in United States marathons. Med Sci Sports Exerc 2012;1843-5.

6. Harmon KG, Drezner JA, Wilson MG, et al. Incidence of sudden cardiac death in athletes: a state of the art review. Br J Sports Med 2014;48:1185-92.

7. Risgaard B, Winkel BG, Jabbari R, et al. Sports-related sudden cardiac death in competitive and non-competitive athlete population aged 12-49 years: data from an unselected nationwide study in Denmark. Heart Rhythm 2014;11:1673-81.

8. Go AS, Mozaffarian D, Roger VL, et al. American Heart Association Statistics Committee and Stroke Statistics Subcommittee. Heart disease and stroke statistics-2014 update: a report from the American Heart Association. Circulation 2014;129:399-410. http:// circ.ahajournals.org,

9. Kratz A, Lewandrowski KB, Siegel AJ, et al. Effect of marathon running on hematological and biochemical laboratory parameters including cardiac markers. Am J Clin Pathol 2002;118:856-63.

10. Siegel AJ, Silverman LM, Lopez MS. Creatine kinase elevations in marathon runners: relationship to training and competition. Yale $J$ Biol Med 1980;53:275-9.

11. Siegel AJ, Verbalis JG, Clement S, et al. Hyponatremia in marathon runners due to inappropriate arginine vasopressin secretion. $A m \mathrm{~J}$ Med 2007;120:461.e11-7.

12. Saenz AJ, Lee-Lewandrowski E, Wood MJ, et al. Measurement of a plasma stroke biomarker panel and cardiac troponin $\mathrm{T}$ in marathon runners before and after the 2005 Boston marathon. Am J Clin Pathol 2006;126:185-9.

13. Empana JP, Jouven X, Canouï-Poitrine $F$, et al. C-reactive protein, interleukin-6, fibrinogen and risk factors of sudden death in 
European middle-aged men: the PRIME study. Arterioscler Thromb Vasc Biol 2010;30:2047-52.

14. Kaptoge S, DiAngelantonio E, Wood AM, et al., Emerging Risk Factors Collaboration. C-reactive protein, fibrinogen, and cardiovascular disease prediction. N Engl J Med 2012;367:1310-20.

15. Siegel AJ, Stec JJ, Lipinska I, et al. Effect of marathon running on inflammatory and hemostatic markers. Am J Cardiol 2001;88:35-8.

16. Kratz A, Wood MJ, Siegel AJ, et al. Effects of marathon running on platelet activation markers: direct evidence for in vivo platelet activation. Am J Clin Pathol 2006;125:296-300.

17. Neilan TG, Januzzi JL, Lee-Lewandrowski E, et al. Myocardial injury and ventricular dysfunction related to training adequacy among non-competitive participants in the Boston Marathon. Circulation 2006;114:2325-33.

18. Libby $P$, Crea F. Clinical implications of inflammation for cardiovascular primary prevention. Eur Heart J 2010;31:777-83.

19. Maddox TM, Stanislowski MA, Grunwald GK, et al. Nonobstructive coronary artery disease and risk of myocardial infarction. JAMA 2014;312:1756-63.

20. Albano AJ, Thompson PD, Kapur NK. Acute coronary thrombosis in Boston marathon runners. N Engl J Med 2012;366:184-5.

21. Thygesen K, Alpert JS, Jaffe AS, et al. Third universal definition of myocardial infarction. Circulation 2012;126:2020-35.

22. Albert CM, Mittelman MA, Chae CU, et al. Triggering of sudden death from cardiac causes by vigorous exertion. $N$ Engl J Med 2000;343:1355-61.

23. Varvarigou V, Farioli A, Korre M, et al. Law enforcement duties and sudden cardiac death among police officers in the United States: case distribution study. BMJ 2014;349:g6534.

24. Dalager-Pedersen M, Sogaard M, Schonheyder HC, et al. Risk for myocardial infarction and stroke after community-acquired bacteremia: a 20-year population-based cohort study. Circulation 2014;129:1387-96.

25. Chung WS, Lin $\mathrm{CL}, \mathrm{Hsu} \mathrm{WH}$, et al. Scrub typhus increases the risk of developing acute coronary syndrome: a nationwide cohort study. Heart 2014;100:1844-50.

26. Eisen DP, Reid D, McBryde ES. Acetyl salicylic acid usage and mortality in critically ill patients with the systemic inflammatory response syndrome and sepsis. Crit Care Med 2012;40:1761-7.

27. Henderson JT, Whitlock EP, O'Conner E, et al. Low-dose aspirin for prevention of morbidity and mortality from preeclampsia: a systematic evidence review for the U.S. Preventive Service Task Force. Ann Intern Med 2014;160:695-703.

28. Siegel AJ. Pheidippides redux: reducing acute cardiac risk during marathon running. Am J Med 2012;125:630-5.

29. Siegel AJ. The rationale for pre-race aspirin to protect susceptible runners from sudden cardiac death during marathons: Deconstructing the Pheidippides conundrum. World J Cardiovasc Dis 2013;3:17-20.

30. Siegel AJ. Aspirin usage pre-race to prevent cardiac arrest in marathon runners during races. Am J Med 2013;126:e47.
31. Walkey AJ. Preventing cardiovascular complications of acute infection: a missed opportunity? Circulation 2014;129:1375-7.

32. Pignone M, Alberts MJ, Colwell JA, et al. Aspirin for primary prevention of cardiovascular events in people with diabetes. J Am Coll Cardiol 2010;55:2878-85.

33. Halvorsen S, Andreotti F, Berg JM, et al. Aspirin therapy in primary cardiovascular disease prevention. A position paper of the European Society of Cardiology Working Group on Thrombosis. J Am Coll Cardiol 2014;64:319-27.

34. Ogdie A, YiDing Y, Haynes K, et al. Risk of major cardiovascular events in patients with psoriatic arthritis, psoriasis and rheumatoid arthritis: a population-based cohort study. Ann Rheum Dis 2015;74:326-32.

35. Steering Committee of the Physicians' Health Study Research Group. Final report on the aspirin component of the ongoing Physicians' Health Study. N Engl J Med 1989;321:129-35.

36. Cohen SI, Ellis ER. Death and near death from cardiac arrest during the Boston marathon. Pacing Clin Electrophysiol 2012;35:241-4.

37. Mostofsky E, Penner EA, Mittleman MA. Outbursts of anger as a trigger of acute cardiovascular events: a systematic review and meta-analysis. Eur Heart J 2014;35:1404-10.

38. Grosser T, Fries S, Lawson JA, et al. Drug resistance and pseudo-resistance: an unintended consequence of enteric-coated aspirin. Circulation 2013;127:377-85.

39. Boulter J, Noakes TD, Hew-Butler T. Acute renal failure in four Comrades marathon runners ingesting the same electrolyte supplement: coincidence or causation? S Afr Med J 2010;100:1-3.

40. Ray WA, Murray KT, Hall K, et al. Azithromycin and risk of cardiovascular death. N Engl J Med 2012;366:1881-90.

41. Azithromycin poses fatal cardiac risk. FDA warns. http://www.fda gov.medwatch (accessed 3/12/2013).

42. Loriega de Menezes PA. Official Handbook for Runners in the Rio de Janiero Marathon. Rio de Janiero: Marathon Press, 2014.

43. Noakes T. Time to quit that marathon running? Not quite yet! Basic Res Cardiol 2014;109:395

44. Maharam LG, Siegel AJ, Siegel S, et al. IMMDA's health recommendations for runners \& walkers. The International Marathon Medical Directors Association (IMMDA). 20 Mar 2010, Barcelona Spain. http://www.aimsworldrunning.org/articles/

IMMDA_Sudden_death_and_how_to_avoid_it_3.20.10.pdf

45. Siegel AJ. Pre-race aspirin to prevent heart attack and/or cardiac arrest during long distance running. IMMDA Advisory, 2015. Available at: http://www.immda.org

46. Hew-Butler T, Rosner MH, Fowkes-Godek S, et al. Statement of the 3rd international exercise-associated hyponatremia consensus development conference, Carlsbad, California, 2015. Clin J Sport Med 2015;25:303-20.

47. Siegel AJ. Fatal water intoxication and cardiac arrest in runners during marathons: prevention and treatment based on validated clinical paradigms. Am J Med. Published Online First: 21 Apr 2015. doi:10.1016/j.amjmed.2015.03.031 